\title{
A Model of the Reference and Information Service Process
}

An Educators' Perspective

Over the past decade and a half, reference and information services have increasingly moved away from library reference desks and away from libraries' print collections into the electronic world. This article describes a study that addressed two research questions related to the changing reference and information services environment:

1. What are the current trends in the provision of reference and information services in terms of user behaviors, librarian behaviors, and information sources being used?

2. What is the basic model of the current reference process?

Data were gathered via focus group interviews with reference and information service educators and via discussions at a town hall-style meeting of faculty members and doctoral students interested in virtual reference education. The study results indicate a shift toward an increasingly interactive, collaborative reference model, in which both the reference librarian and the reference user play the roles of information seeker, information receiver, and information creator. The article concludes with a model of this process and with a discussion of implications for the provision of reference and information services.

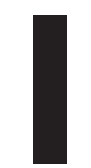

$n$ response to the electronic information explosion, members of the public are increasingly using the Internet and the World Wide Web to search for information to support their personal, business, and other information needs. At the same time, a growing number of libraries are offering reference and information services (RIS) via a variety of virtual technologies, and there has been an increasing shift from faceto-face reference interactions that relied on paper-based information resources to virtual interactions using electronic information resources. It is possible that these developments have changed the ways in which people use RIS and possibly even the ways in which reference providers deliver reference services to their users.

With their inside view on research in this area and with their close connections to practice, RIS educators are in a unique position to assess changes occurring in the field of reference. This study sought to learn from RIS educators their views on the current state of reference services, with a focus on the effects of the online information explosion on the virtual reference process.

\section{RESEARCH QUESTIONS}

Because of this movement from face-toface to virtual venues and from paper to
Denise E. Agosto, Lily Rozaklis, Craig MacDonald, and Eileen G. Abels

Denise E. Agosto is Associate Professor; Lily Rozaklis and Craig

MacDonald are doctoral students; and Eileen G. Abels is Professor and Associate Dean for Academic Affairs, College of Information Science and Technology, Drexel University, Philadelphia. Submitted for review April 6, 2010; accepted for publication May 25, 2010.

Reference \& User Services Quarterly, vol. 50, no. 3, pp. 235-44

(C) 2011 American Library Association. All rights reserved.

Permission granted to reproduce for nonprofit, educational use. 
electronic resources, today's reference transactions take place within a dynamic and rapidly changing information environment. The fundamental question now becomes "what changes, if any, has the exploding digital information environment caused in the reference process?" Without an understanding of these changes, reference providers cannot tailor their services to meet the needs of today's information users.

Two research questions drove this study:

1. What are the current trends in the provision of reference and information services, in terms of user behaviors, librarian behaviors, and information sources being used?

2. What is the basic model of the current reference process?

\section{LITERATURE REVIEW}

There is a large research literature concerning the design and delivery of reference and information services. This review includes recent empirical studies and theoretical analyses related to current trends in the delivery of reference services and major models of the reference process.

There has been no firm consensus on the use of terminology defining virtual and digital in the context of reference service. ${ }^{1}$ Lipow deemed the phrases "virtual reference" and "digital reference" interchangeable. ${ }^{2}$ Lankes and Shostack noted that digital, virtual, and e-reference are the same type of service, in which librarians serve as intermediaries to assist users in finding information in a digital environment. ${ }^{3}$ This article will use the term virtual reference to cover all of these terms.

\section{Trends in the Delivery of Reference and Information Services}

Tenopir and Ennis sent questionnaires to the directors of large academic libraries in the United States and Canada every three years from 1991 to 2001. They identified a number of changes in reference services, including an increase in the range of available electronic resources, a de-emphasis on mediated services, an increase in the range of available online services, an increase in the web as the standard platform for resources and services, a decrease in the number and an increase in the complexity of questions, and an increase in users' computer skills. ${ }^{4}$ To be sure, virtual reference services are now standard offerings in most public, academic, and large special libraries. Lankes has suggested that "digital reference is a phenomenon that is firmly rooted and ever-expanding in practice. ${ }^{5}$ He proposed a digital reference research agenda that combined the examination of policies, systems, evaluation, and behaviors to examine a central question: "How can human expertise be incorporated effectively and efficiently into information systems to answer information seekers' questions?"

It's not just reference services that are increasingly digital in nature, but the sources used in virtual reference work as well. Shachaf and Shaw analyzed 1,851 e-mail and chat reference transcripts from one academic and one public library and found that 96 percent of the sources used in the responses were electronic. ${ }^{7}$ Similarly, a study by Bradford, Costello, and Lenholt showed that only 1.8 percent of an academic library's 9,587 titles in the print collection were used to answer reference questions, and that academic reference used online sources significantly more than print sources. $^{8}$

Many studies have examined specific aspects of virtual reference services, focusing on issues such as reference interviewing techniques, verbal and nonverbal communication strategies, and teaching practices. ${ }^{9}$ Additionally, studies have reported on collaboration during the research process and on instruction to users. ${ }^{10}$

Other studies have evaluated reference transcripts to assess librarian performance, questionanswering success, user satisfaction, and answer completeness and accuracy. ${ }^{11}$ Unobtrusive analyses of reference data have looked to categorize the types of questions posed to virtual reference services. ${ }^{12}$ Still other related work has studied the expansion of RIS into new technologies, such as instant messaging (IM), text messaging or SMS, and Second Life. ${ }^{13}$

\section{Major Models of Reference and Information Services}

A number of researchers have proposed models of the reference process. The traditional face-to-face reference service model anchors the interaction between the user and the librarian in some service point, typically a reference desk. In this environment, a library user may approach a reference librarian with an inquiry of any type or complexity. ${ }^{14}$ While this model symbolizes values including "ease of access, equity, and high-quality service," the disadvantages include inflexibility in the use of library staff, duplication of effort, lack of accountability, high cost, and reinforcement of the image of librarian as clerk. ${ }^{15}$

Tiered reference service has been described as an alternate to the traditional model, often dividing 
the reference desk into two or more service points. Initially made popular by the Brandeis model, the tiered reference model's defining feature is that paraprofessionals or trained student assistants answer a majority of simple reference questions so that reference librarians may be reserved for handling more demanding research questions. ${ }^{16}$

Another influential model of reference involves the role of reference librarians in questionanswering activities versus their role in providing instruction to users. With the liberal, or maximum, model, the librarian's responsibility centers on delivering an answer in response to a user's inquiry. The librarian does not attempt to educate the user in the process; rather, he or she puts all effort into finding accurate and credible information. Conversely, the ultimate goal for the conservative, or minimal, model is to train users to make use of the library independently, as the process of finding information is valued above the information itself. Despite the conflicting objectives of the liberal and conservative models, the approaches may coexist in practice. ${ }^{17}$

With the increased availability of technologies and the drive to increase library staff efficiency and reduce costs per reference transaction, some libraries have adopted the Call Center model. ${ }^{18}$ In this model library staff operate as "agents ... tak[ing] calls at computer workstations where they ... have ready access to databases, lists of frequently-asked questions and answers, prewritten scripts for particular situations, and other tools needed to deliver ... information." 19

In academic libraries, a dynamic model of reference service has been termed "information commons." On one level the phrase describes an "exclusively online environment in which the widest possible variety of digital services can be accessed via a single interface," while concurrently denoting "a new type of physical facility ... designed to organize workspace and service delivery around the integrated digital environment." ${ }^{20}$ This model reflects the ways in which academic libraries are responding to the demands for technology, combining information resources and reference assistance, and creating collaborative workspaces for acquiring and shaping knowledge. ${ }^{21}$ Most recently, Pomerantz et al. presented a model of the virtual reference process that highlighted five key question-handling functions: question acquisition, triage, answer formulation, tracking, and resource creation. $^{22}$

While each of these models is useful for thinking about reference services in the current information environment, what is missing from the literature is a model of the entire reference process, including both librarian and user behaviors, that takes into account the recent changes in the information environment. This study sought to fill that gap by creating a model that brings together librarian and user behaviors to provide a full picture of the impact of the electronic information explosion on the reference process.

\section{METHODS}

Data for this study were gathered using two methods: focus group interviews and a town hall meeting. For the focus group interviews, a list of faculty who teach courses related to RIS and digital libraries was compiled based on a review of the websites of ALA-accredited master's programs. Sixteen participants from thirteen universities took part in three focus groups held from January 2008 through January 2009 at the annual meetings of the American Society for Information Science and Technology (ASIS\&T) and of the Association for Library and Information Science Educators (ALISE). There were four faculty members in the first focus group, five in the second group, and seven in the final group. Their experience teaching reference and digital libraries courses ranged from one year to more than thirty years. Six participants had been teaching reference for one to five years; six had been teaching for six to ten years; and four had been teaching reference for eleven or more years. They came from a range of academic ranks. Five held the title of instructor or lecturer; three were assistant professors; five were associate professors; two were professors; and one was an associate dean. Each focus group session lasted between one and one and a half hours.

The focus group guide was divided into five sections: (1) introductions, (2) curricular coverage of digital/remote reference, (3) barriers to teaching reference, (4) future of reference services, and (5) conclusions. The sessions were audio taped and later transcribed for analysis.

To triangulate the focus group data and to increase the number of participants providing data, the researchers collected additional data at the ALISE 2009 annual meeting from audience members at a town hall-style meeting of faculty members and doctoral students interested in virtual reference education. It was advertised through the ALISE conference program, and approximately fifty-five people attended and took part in the discussion. The session consisted of a panel-led group discussion of four topics related to virtual reference and information services: (1) current LIS curricula for digital reference, (2) barriers and 
obstacles to teaching digital reference, (3) future directions of digital reference services, and (4) ideas about how LIS education can best reflect the future direction of digital reference services. Several note takers were present to record the responses and discussion. The notes were compiled and transcribed for analysis.

The focus group transcripts and the transcribed town hall meeting notes were analyzed using the constant comparative method, the most common method for analyzing qualitative data. The constant comparative method involves repeatedly reading through a set of data, grouping and regrouping individual pieces of data into categories to create a coding scheme that addresses the research questions. ${ }^{23}$ Typically, analysis of the resulting coding scheme leads to the creation of a typology, model, analogy, or other method of presenting the data.

\section{FINDINGS}

The resulting coding scheme included six major themes relating to the current and future state of virtual reference: (1) the convergence of multiple modes of reference, (2) the burgeoning range of information resources, (3) reference as a collaborative process, (4) reference in the library 2.0 mode, (5) the shift from librarian-as-searcher to librarianas-evaluator, and (6) the possible demise of ready reference. These six themes are explained below with supporting literature from previous studies where applicable.

\section{The Convergence of Multiple Modes of Reference}

Rather than viewing face-to-face reference, chat reference, IM reference, e-mail reference, telephone reference, and so on as unique services, each one separate from the others in staff and resources, the trend seems to be to view them all as subsets of "reference and information services," or "question-answering services." As one focus group participant explained, "the trend is toward thinking how to integrate." While the use of each mode of delivery might require some variant skills and techniques, they are all part of what one focus group participant labeled "the reference continuum."

One of the town hall meeting participants pointed out that the traditional practice was for librarians to respond using the medium that the user had chosen to contact the librarian. Over the past decade or so, many librarians have been moving toward responding using the most appropriate medium for answering the question, regardless of the initial medium of contact. For example, if a user calls a library to ask a fairly complicated question, the librarian might choose to research the question and respond via e-mail to create a written record of the response, instead of automatically responding via the phone.

This trend toward the convergence of reference media seems to be occurring in both public and academic libraries. In speaking about academic libraries, one focus group participant said that

the trend in a lot of academic libraries is consolidation of service points, so at every level we're having to anticipate that our students will be involved in all these modes of delivery. They're not going to be able to specialize in digital reference in most settings, or in telephone, or face-to-face.

The other group members agreed that the same is true for public libraries.

The convergence of reference modes is creating multitasking problems for many librarians, and as a result, today's reference librarians must multitask on a nearly continual basis. As one of the focus group participants said, "If you're on the desk, you're also answering the phone. You may be doing chat while you're also having to monitor e-mail ... and there's no opportunity to handle just one patron at a time."

\section{The Burgeoning Range of Information Resources}

The traditional face-to-face reference desk existed in an environment where information resources were physically concentrated. The reference librarian-in many ways operating as a gatekeeper-was well-versed on the content, location, and accessibility of these resources, and a familiarity and working knowledge of sources was considered fundamental to the field..$^{24}$ Because most of the sources reference librarians are using today are digitally based, the sources for virtual and face-toface reference tend to be the same, and they cover a wider range of formats and types than ever before. As one participant explained:

The person in the public library used to [be able to use just print resources] because every information universe used to be covered in that small print collection. Now [independent of the] environments in which they're functioning, librarians have all these modes of answering questions, and in many cases, 
a much wider range of resources that they

have to make sense of.

Reference librarians have increasingly incorporated these digital resources into their library collections and interactions with users. Tenopir and Ennis' surveys indicated that from 1991 to 2001, research libraries shifted emphasis in their reference collections from print to electronic formats, noting that in 2001 nearly 90 percent offered multiple online services to end users, including bibliographic resources and full-text access to periodicals, whereas in 1991 the figure was just 45 percent. $^{25}$

\section{Reference as a Collaborative Process}

The focus group participants and the town hall meeting participants agreed that collaboration is occurring more frequently at all stages of the reference process and among all types of reference users. They thought that reference soon is likely to become "an even more collaborative process"becoming more "collaborative on both ends." This includes collaboration between multiple users working together to ask questions of shared interest, between multiple librarians working together on formulating answers to give to one or more users, and even between users and librarians collaborating during the question answering and research stages.

In the research literature, collaboration has most often referred to multiple libraries answering a shared pool of questions. ${ }^{26}$ Kwon identified some of the problems created by multi-institution question sharing, such as difficulty in answering questions concerning local libraries' collections and services. ${ }^{27}$ Pomerantz asserted that "the model of the reference transaction as a one-to-one interaction is overly simplistic," and that "as network technology is increasingly utilized in reference work, reference work will become fundamentally a collaborative effort. ${ }^{28} \mathrm{He}$ discussed librarian collaboration within a number of different modes, focusing on the librarian end of the reference process.

There is evidence that collaboration at the users' end of the reference/research process also is on the rise. A number of academic libraries, such as the Indiana State University library, are designing new collaborative in-house work spaces for groups of students and faculty working within the library building. ${ }^{29}$ Aldrich observed that "many libraries continue to overlook the fact that the collaboration taking place between group members is often mediated or moderated by technology." ${ }^{30}$ He suggested that support of collaboration should be taken into account when designing technological infrastructure in libraries, such as computer work stations.

\section{Reference in the Library 2.0 Mode}

Not only are the question-and-answering and research processes becoming increasingly collaborative, users are playing an increasing role in information production. According to one of the focus group participants, reference is heading toward "library 2.0 . . in terms of the user involvement." Just as library 2.0 means providing library services that encourage feedback and participation from patrons, reference 2.0 means users acting as information providers as well as information seekers, creating resources such as personal blogs, adding to library collaborative blogs and wikis, reviewing materials to be posted on library websites, and so on, as a part of what one town hall meeting participant called "the people's network."

This also means a shift in reference collection development beyond the inclusion of high quality, professionally-produced information resources to include other forms of content, including wikis and blogs generated by members of the general public. Librarians now have to decide how much user-generated content should be added to their online collections and what kinds of selection criteria to apply to these types of materials. Many librarians are also creating online content, such as library blogs, podcasts, and other materials.

\section{The Shift from Librarian-as-Searcher to Librarian-as-Evaluator}

Now that many users have become more adept at finding information, some of the study participants saw a shift in the reference librarian's role from a focus on the librarian-as-searcher to a focus on the librarian-as-evaluator. As one participant explained, "Evaluation and the use of information is increasingly important, not just the search."

In today's information environment, librarians teach users how to evaluate source quality and credibility more than how to locate sources. As one participant said,

One of the key components [of today's reference work] is our ability to evaluate what is a valid site, what is valid content, and how does it relate to the question that was asked? That is something that I think is a specialization that [librarians] have and... that needs to be focused on and emphasized. [Librarians] will always be very important .. . because we can say, "This is it and you 
can find it here. It's a site that we're willing to put our name behind or to put our authority behind because we've evaluated it."

Another participant explained that "today it is more important than in the past to teach people how to evaluate the information and then ask them how they will use it."

Evaluation is not a new role for librarians. As Cullen explained, "Careful attention to the quality and scope of resources has been a constant theme of reference specialists and educators since the earliest days of reference as a separate library activity." ${ }^{\prime 1}$ What is new is the degree of importance of evaluation during the reference process. Indeed, Tenopir and Ennis concluded that "helping students evaluate the resources they use has also become more important." ${ }^{2} 2$ The concept of librarian-as-evaluator demonstrates the value that librarians add to the self-directed information searching process and emphasizes the educational role of the reference librarian.

The study participants generally assumed that instruction was a fundamental part of reference and information services. As one focus group participant said, the concept of instruction "is so simple to librarianship these days," highlighting the central role of instruction in today's reference work. Another focus group participant stated that "every [reference] interaction is an opportunity for teaching and providing instruction." He went on to explain that providing instruction in faceto-face reference is fairly straight forward, but this is often not the case in online environments. As a result, the new question has become how to provide instruction in new and emerging reference environments, especially in asynchronous media.

For at least the past decade in published discussions of the state of reference services, instruction has featured prominently as a core concept, particularly in the academic library world. For example, LaGuardia identified library instruction as one of five crucial issues in contemporary reference services..$^{33}$ And in his prediction of the future of reference services, Tyckoson forecasted that "the demand for instruction will rise," explaining that "the community needs the librarian to teach how to find and, more importantly, how to evaluate information sources." 34

\section{The Possible Demise of Ready Reference}

Lastly, some of the study participants suggested that due to the wider availability of information on the Internet, "everybody has turned into a reference librarian," and "ready reference is dead."
This means that "reference questions are turning into research questions, and that makes librarians and information professionals more important, not less important." Others disagreed and suggested that while ready reference may be on the decline or even extinct in some types of libraries, it is still alive and well in public libraries.

The literature lends mixed support to this idea of a reduction in ready reference work. One change that Tenopir and Ennis saw during the period of their study (1991-2001) was libraries reporting at the end of the survey period that questions were taking longer on average to answer because they tended to get more complex as the years passed. ${ }^{35}$ Tyckoson agreed that this is the direction of the trend and forecasted that as reference work continues to evolve, "the demand for factual information will decrease." 36

On the other hand, using 2003 and 2004 virtual reference data, De Groote et al. reported that ready reference questions accounted for 37 percent of the questions received at the University of Illinois at Chicago's collaborative reference system. ${ }^{37}$ Other researchers have found ready reference to account for much smaller percentages of the total number of virtual reference questions posed. For example, Arnold and Kaske found only 14 percent of 419 academic library chat reference transactions involved ready reference questions, and Kwon labeled just 1.4 percent of the questions as ready reference in her public library chat reference study. ${ }^{38}$

Much of the quantitative variance in these studies can probably be attributed to variant definitions of "ready reference," leaving it unclear just how common ready reference questions are today. There is wider agreement that research-type reference questions have become more complicated since the popularization of the Internet. ${ }^{39}$ Janes concluded that

I think we may be the last generation of reference librarians who could concentrate on ready reference as a major component of their work lives. I think what we call ready reference-quick, factual answers to specific questions-will always be a part of librarianship, but a diminishing part, and, in the information world that looks to be emerging, it does not make a lot of sense to have that as a primary focus. ${ }^{40}$

\section{A MODEL OF REFERENCE AND INFORMATION SERVICES}

The final step in the data analysis process involved forming these six major themes into a model of 
reference and information services, shown in figure 1 . As indicated in this model, the library user is now playing the part of reference provider as well as reference user, and the reference librarian is now playing the part of information receiver as well as information provider. As in decades past, a reference transaction still begins with a user submitting a query to a librarian, although more often the user has conducted an initial search before contacting the librarian. Even after the transaction with the librarian has begun, the user may concurrently search for information on his/her own, as indicated in figure 1 by the "search" and "research" arrows extending from "user" to "information resources." As such, this process is more often a collaborative effort between the users and the librarians, with the users searching and retrieving information throughout the transaction and the librarians searching, researching, filtering, and evaluating throughout the transaction. These collaborative efforts enable increased opportunities for instructing users on searching, evaluating, and other aspects of the process. While users often searched for information throughout the reference process in the past, user searching tends to occur more frequently today, as well as being more extensive in nature.

In this model, the available information resources vary widely in format, as indicated by the various information resource types listed in the upper right rectangle in the visual model. These resources include user-created content made available in blogs, wikis, and other social media platforms, as indicated by the "create" arrow between "user" and "information resources." The line for the "create" arrow is dotted to indicate that while users are now becoming creators of information that is sometimes used during the reference process, the act of creating that content takes place outside of the reference process. The same holds true for the dotted "create" arrow connecting the "librarian" to "information resources." Today's librarians create many types of information resources, such as blogs and video clips, and again, this information resource creation supports the reference process but occurs outside of it. Aided by the explosion of diverse information and information resources accessible via the web, librarians' roles now focus more heavily on filtering and evaluating resources for authority, accuracy, currency, and other indicators of trustworthiness than on providing answers to questions.

Moreover, in this model the librarian may employ multiple modes of communication to interact with users, responding to them using new or emerging technologies, as indicated by the various media types listed in the lower right rectangle

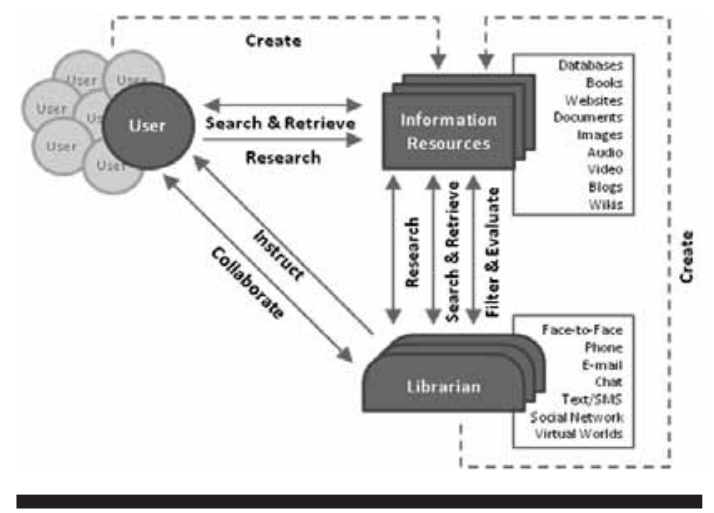

Figure 1. A Model of the Reference Process

of the visual model. Finally, as indicated by the "research" arrows, the types of questions received are becoming increasingly complex in nature and are requiring deeper levels of research by both the user and librarian.

What does this model indicate about the evolving role of the reference librarian? With the explosion of digital information, the function of reference librarians has shifted to "filtering and selecting, given that information, usually in large quantity, can be easily found on almost any topic." ${ }^{41}$ This complex online information environment has other ramifications for the work of information professionals, including spending more time per reference transaction. As Tenopir reported, "Enhanced searching abilities plus the addition of material we never had access to [before] makes it more difficult to give up on a question. We often go much further." ${ }^{42}$ This broader information milieu has led to the concept of "reference overload," when a librarian inadvertently offers too many pertinent resources to a user. Reichardt explained that "in a digital world where access to resources is available at light speed, the temptation may be to push as many of these resources as are available toward the user... which could potentially overwhelm the user." ${ }^{43}$

Nearly a decade and a half ago, a symposium on the future of reference led to the conclusion that reference services were moving toward an increased emphasis on user education and on the role of the librarian as a tool builder for reference technologies. ${ }^{44}$ The model presented here represents a thrust forward in libraries' ongoing evolution toward an ever-increasing "focus on the users." ${ }^{45}$ Instead of users going to reference desks to ask questions, today's reference librarians, according to one of the town hall meeting participants, "have to reach users where they are," and they must reach them via users' ever-changing technologies of choice. Of course, the best way 
to identify users' technologies of choice is to ask them, making user input crucial to the successful provision of virtual reference and information services.

It is important to emphasize that this research represents a specific perspective on the reference process, that of reference and information service educators. Input from librarians is crucial to understanding how these issues play out in various library environments. Now that the model has been developed, the next stages in this research process are to seek input from librarians working in the field of RIS and to validate the model presented here in a variety of reference settings. The participants in this research project were mainly public library experts and, to a lesser extent, academic library experts. Therefore the model is likely the most applicable to public library settings, and further research is needed to identify any differences in the reference process based on type of library.

\section{CONCLUSION}

Lankes has suggested that researchers who study virtual reference issues need to think of reference services less in terms of question answering and more in terms of research and information selection and evaluation assistance. ${ }^{46}$ As these roles continue to evolve, the challenge will be to design and implement appropriate technologies that can support and enhance them based on users' needs and preferences and then to incorporate these technologies into reference education.

Overall, the results of this study point to an ongoing shift toward a more interactive, collaborative reference model, in which both the reference librarian and the reference user play the roles of information seeker, information receiver, and even information creator. Although RIS are moving more and more toward digital environments, this study suggests that reference services as a whole are not in danger of being eliminated any time soon. While librarians might be called upon less for assistance in the mechanics of basic information searching, they are now needed more than ever for their expertise in teaching users about the nature of modern information, for sharing their knowledge of the wide range of available information resources, for collaborating with users during the various stages of the search and research process, and for evaluating information quality.

\section{ACKNOWLEDGEMENTS}

This research was supported by a grant from the Institute for Museum \& Library Services (IMLS) under the Laura Bush 21st Century Librarian Grants. The contents of this article do not carry the endorsement of IMLS. The opinions expressed in this article are those of the researchers.

\section{References and Notes}

1. Joseph Janes, "An Informal History (and Possible Future) of Digital Reference," Bulletin of the American Society for Information Science \& Technology 34, no. 2 (Dec. 2007/Jan. 2008): 8-10.

2. Anne Grodzins Lipow, The Virtual Reference Librarian's Handbook (New York: Neal-Schuman, 2003).

3. R. David Lankes and Pauline Shostack, "The Necessity of Real-Time: Fact and Fiction in Digital Reference Systems," Reference \& User Services Quarterly 41, no. 4 (Summer 2002): 350-55.

4. Carol Tenopir and Lisa A. Ennis, "Reference Services in the New Millennium," Online 25, no. 4 (July/Aug. 2001): 40-45.

5. R. David Lankes, "The Digital Reference Research Agenda," Journal of American Society for Information Science E Technology 55, no. 4 (Feb. 15, 2004): 311.

6. Ibid., 303.

7. Pnina Shachaf and Deborah Shaw, "Bibliometric Analysis to Identify Core Reference Sources of Virtual Reference Transactions," Library \& Information Science Research 30, no. 4 (Dec. 2008): 291-97.

8. Jane T. Bradford, Barbara Costello, and Robert Lenholt, "Reference Service in the Digital Age: An Analysis of Sources Used to Answer Reference Questions," Journal of Academic Librarianship 31, no. 3 (May 2005): 263-72.

9. See, for example, Eileen G. Abels, "The E-mail Reference Interview," RQ 35, no. 3 (Spring 1996): 345-58; Joseph Janes and Joanne Silverstein, "Question Negotiation and the Technological Environment," D-Lib Magazine 9, no. 2 (February 2003), www.dlib.org/ dlib/february03/janes/02janes.html (accessed January 12, 2010); Jody C. Fagan and Christina M. Desai, "Communication Strategies for Instant Messaging and Chat Reference Services," The Reference Librarian 38 (2003): 121-55; Jung-Ran Park, "Interpersonal and Affective Communication in Synchronous Online Discourse," The Library Quarterly 77, no. 2 (Apr. 2007): 133-55; Marie L. Radford, "Encountering Virtual Users: A Qualitative Investigation of Interpersonal Communication in Chat Reference," Journal of the American Society for Information Science E Technology 57, no. 8 (June 2006): 1046-59; Denice Adkins and Sandra Erdelez, "An Exploratory Survey of Reference Source Instruction in LIS Courses," Reference \& User Services Quarterly 46, no. 2 (Winter 2006): 50-60; Lorri Mon et al., "Remote Reference in U.S. Public Library Practice and LIS Education," Journal of Education for Library and Information Science 49, no. 3 (Summer 2008): 180-94; David Ward, "Using Virtual Reference Transcripts for Staff Training," Reference Services Review 31, no. 1 (2003): 46-56.

10. See, for example, Alan W. Aldrich, "Creating Collaborative Workstations for Reference and Public Use in Academic Libraries," College \& Undergraduate Libraries 15, no. 3 (2008): 364-77; Terri P. Summey and Cynthia Akers, "From IM to Collaboration: Providing Virtual Reference Services at a Medium-Sized Institution," College \& Undergraduate Libraries 13, no. 4 (Mar. 2006): 75-95; Patricia E. Johnston, "Digital 
Reference as an Instructional Tool: Just in Time and Just Enough," Searcher 11, no. 3 (Mar. 2003): 31-33; Martha Portree et al., "Overcoming Transactional Distance: Instructional Intent in an E-mail Reference Service," Reference \& User Services Quarterly 48, no. 2 (Winter 2008): 142-52; Laura Taddeo and Jill M. Hackenberg, "The Nuts, Bolts, and Teaching Opportunities of Real-Time Reference," College \& Undergraduate Libraries 13, no. 3 (Oct. 2006): 63-85.

11. See, for example, Loree Hyde and Caleb TuckerRaymond, "Benchmarking Librarian Performance in Chat Reference," The Reference Librarian 46 (2006): 5-19; Julie Arnold and Neil Kaske, "Evaluating the Quality of a Chat Service," portal: Libraries and the Academy 5, no. 2 (Apr. 2005): 177-93; Nahyun Kwon, "Public Library Patrons' Use of Collaborative Chat Reference Service: The Effectiveness of Question Answering by Question Type," Library \& Information Science Research 29, no. 1 (Mar. 2007): 70-91; Jo Bell Whitlatch, "Evaluating Reference Services in the Electronic Age," Library Trends 50, no. 2 (Fall 2001): 207-217; Matthew R. Marsteller and Danianne Mizzy, "Exploring the Synchronous Digital Reference Interaction for Query Types, Question Negotiation, and Patron Response," Internet Reference Services Quarterly 8, no. 1/2 (2003): 149-65; David Robins and Jonathan Miller, J., "Evaluation of Synchronous Digital Reference Services," The 5th Virtual Reference Desk Conference, San Antonio, TX, Nov. 17-18, 2003, www.webjunction.org/c/ document_library/get_file?folderId=441345\&name= DLFE-11951.pdf (accessed Jan. 14, 2010); Stephen Lochore, "How Good are the Free Digital Reference Services? A Comparison of Library-Based and Expert Services," Library Review 53, no. 1 (2004): 24-29; David Ward, "Measuring the Completeness of Reference Transactions in Online Chats: Results of an Unobtrusive Study," Reference \& User Services Quarterly 44, no. 1 (Fall 2004): 46-56.

12. See, for example, Wendy Diamond and Barbara G. Pease, "Digital Reference: A Case Study of Question Types in an Academic Library" Reference Services Review 29, no. 3 (2001): 210-18; Joseph Fennewald "Same Questions, Different Venue: An Analysis of InPerson and Online Questions," The Reference Librarian 46 (2006): 20-35; Deborah B. Henry and Tina M. Neville, "Testing Classification Systems for Reference Questions," Reference \& User Services Quarterly 47, no. 4 (Summer 2008): 364-73; Marsteller and Mizzy, "Exploring the Synchronous Digital Reference Interaction for Query Types, Question Negotiation, and Patron Response"; Jennifer Schwartz, "Toward a Typology of E-mail Reference Questions," Internet Reference Services Quarterly 8, no. 3 (2003): 1-15; JoAnn Sears, "Chat Reference Service: An Analysis of One Semester's Data," Issues in Science and Technology Librarianship 32 (Fall 2001), www.istl.org/01-fall/ article2.html (accessed Jan. 3, 2010)

13. See, for example, Marshall Breeding, "Instant Messaging: It's Not just for Kids Anymore," Computers in Libraries 23, no. 10 (Nov./Dec. 2003): 38-40; Marianne Foley, "Instant Messaging Reference in an Academic Library: A Case Study," College \& Research Libraries 63, no. 1 (Jan. 2002): 36-45; J. B. Hill, Cherie Madarash Hill, and Dayne Sherman, "Text Messaging in an Academic Library: Integrating SMS into Digital Reference," The Reference Librarian 47, no. 1 (2007): 17-29; Jacquelyn Erdman, "Reference in a 3-D Virtual World: Preliminary Observations on Library Outreach in 'Second Life," The Reference Librarian 47, no. 2 (2007): 29-39; Rebecca Hedreen et al., "Exploring Virtual Librarianship: Second Life Library 2.0," Internet Reference Services Quarterly 13, no. 2/3 (Spring 2008): 167-96.

14. For example, Barbara Robinson, "Reference Services: A Model of Question Handling," RQ 29, no. 1 (Fall 1989): 48-62.

15. Chris D. Ferguson and Charles A. Bunge, "The Shape of Services to Come: Value-Based Reference Service for the Largely Digital Library," College \& Research Libraries 58, no. 3 (May 1997): 253; William L. Whitson, "Differentiated Service: A New Reference Model," Journal of Academic Librarianship 21, no. 2 (Mar. 1995): 103-110.

16. Kerryn A. Brandt, Jayne M. Campbell, and Willard F. Bryant, "Reflections on Reference Services," Journal of American Society for Information Science 47, no. 3 (Mar. 1996): 210-16.

17. John W. Fritch and Scott B. Mandernack, "The Emerging Reference Paradigm: A Vision of Reference Services in a Complex Information Environment," Library Trends 50, no. 2 (Fall 2001): 286-305.

18. Steve Coffman and Matt L. Saxton, "Staffing the Reference Desk in the Largely Digital Library," in From Past-Present to Future-Perfect: A Tribute to Charles A. Bunge and the Challenges of Contemporary Reference Service, ed. C. D. Ferguson (New York: Haworth Press, 1999): 141-63; Chris D. Ferguson, "'Shaking the Conceptual Foundations' Too: Integrating Research and Technology Support for the Next Generation of Information Service," College \& Research Libraries 61, no. 4 (July 2000): 300-311; Susan McGlamery and Steve Coffman, "Moving Reference to the Web," Reference \& User Services Quarterly 39, no. 4 (Summer 2000): 380-86.

19. Coffman and Saxton, "Staffing the Reference Desk in the Largely Digital Library," 48.

20. Donald Beagle, "Conceptualizing an Information Commons," The Journal of Academic Librarianship 25, no. 2 (Mar. 1999): 82-89.

21. Laurie A. MacWhinnie, "The Information Commons: The Academic Library of the Future," portal: Libraries and the Academy 3, no. 2 (Apr. 2003): 241-57.

22. Jeffrey Pomerantz et al., "The Current State of Digital Reference: Validation of a General Reference Model through a Survey of Digital Reference Services," Information Processing and Management 40, no. 2 (Mar. 2004): 347-63.

23. Barney G. Glaser and Anselm L. Strauss, The Discovery of Grounded Theory: Strategies for Qualitative Research (Hawthorne, NY: Aldine de Gruyter, 1967); Yvonne Lincoln and Egon Guba, Naturalistic Inquiry (Newbury Park, Calif.: Sage, 1985).

24. For example, Benjamin O. Alafiatayo, Yau J. Yip, and John C. P. Blunden-Ellis, "Reference Transaction and the Nature of the Process for General Reference Assistance," Library \& Information Science Research 18 (Autumn 1996): 357-84.

25. Carol Tenopir and Lisa A. Ennis, "Reference Services in the New Millennium."

26. For example, Sandra L. De Groote, Josephine L. Dorsch, Scott Collard, and Carol Scherrer, "Quantifying Cooperation: Collaborative Digital Reference Service in the Large Academic Library," College \& 


\section{FEATURE}

Research Libraries 66, no. 5 (Sept. 2005): 436-54; Kwon, "Public Library Patrons' Use of Collaborative Chat Reference Service."

27. Kwon, "Public Library Patrons' Use of Collaborative Chat Reference Service."

28. Jeffrey Pomerantz, "Collaboration as the Norm in Reference Work," Reference \& User Services Quarterly 46, no. 1 (Fall 2006): 45.

29. Ralph B. Gabbard, Anthony Kaiser, and David Kaunelis, "Redesigning a Library Space for Collaborative Learning," Computers in Libraries 27, no. 5 (May 2007): 6-11.

30. Aldrich, "Creating Collaborative Workstations for Reference and Public Use in Academic Libraries," 365.

31. Rowena Cullen, "The Evolution of Information Services," International Yearbook of Library and Information Management (IYLIM) 2001/2002, www.facetpublishing .co.uk/infoservs.pdf (accessed Jan. 3, 2010): 11

32. Tenopir and Ennis, "Reference Services in the New Millennium," 44.

33. Cheryl LaGuardia, "The Future of Reference: Get Real!" Reference Services Review 31, no. 1 (2003): 39-42.

34. David Tyckoson, "On the Desirableness of Personal Relations between Librarians and Readers: The Past and Future of Reference Service," Reference Services Review 31, no. 1 (2003): 15
35. Tenopir and Ennis, "Reference Services in the New Millennium."

36. Tyckoson, "On the Desirableness of Personal Relations between Librarians and Readers," 15.

37. De Groote et al., "Quantifying Cooperation."

38. Arnold and Kaske, "Evaluating the Quality of a Chat Service"; Kwon, "Public Library Patrons' Use of Collaborative Chat Reference Service."

39. For example, LaGuardia, "The Future of Reference"; Joseph Janes, "What is Reference for?" Reference Services Review 31, no. 1 (2003): 22-25.

40. Janes, "What is Reference for?" 24

41. David Bawden and Lyn Robinson, "The Dark Side of Information: Overload, Anxiety, and Other Paradoxes and Pathologies," Journal of Information Science 35 no. 2 (Apr. 2009): 182.

42. Carol Tenopir, "Plagued by Our Own Successes," Library Journal 123 (Mar. 1, 1998): 40.

43. Randy Reichardt, "Digital Reference Overload: Thoughts on How to Deal," Internet Reference Service Quarterly 11, no. 2 (2006): 111.

44. Keith Ewing and Robert Hauptman, "Is Traditional Reference Service Obsolete?" Journal of Academic Librarianship 21, no. 4 (Jan. 1995): 3-6.

45. Tyckoson, "On the Desirableness of Personal Relations between Librarians and Readers," 14.

46. Lankes, "The Digital Reference Research Agenda." 